\title{
ÍNDICE DE ÁREAS VERDES PARA MACROZONA DE CONSOLIDAÇÃO DE PARANAVAÍ - PR
}

\author{
Rose Hélida Astolfo Freire ${ }^{1}$; Elizete Besagio Calegari²; Luiz Eduardo Correa ${ }^{3}$; Bruno Luiz \\ Domingos De Angelis ${ }^{4}$
}

(recebido em 29.01.2011 e aceito para publicação em 15.03.2012)

\section{RESUMO}

A qualidade ambiental e de vida são fatores prejudicados no processo de expansão das áreas urbanas. A vegetação exerce papel relevante na amenização dos efeitos prejudiciais da urbanização, através de suas funções ambientais, estéticas e sociais, promovendo melhorias tanto na condição ambiental como na de vida da população citadina. A pesquisa procurou avaliar quali-quantitativamente a oferta de Áreas Verdes em três Zonas (1, 2 e 3) de Paranavaí-PR. Para tanto utilizou-se, num primeiro momento, o cálculo do Índice de Áreas Verdes (IAV) considerando as áreas, independentemente do aspecto qualitativo. Posteriormente, realizou-se análise qualitativa destas áreas e recalculou-se o IAV. Através do primeiro cálculo, constatou-se reduzida presença de Áreas Verdes para as três Zonas, especialmente nas Zonas 1 e $3 \mathrm{com} 0$ (zero) $\mathrm{m}^{2} / \mathrm{hab}$. A partir da análise qualitativa verificouse em todas as Áreas Verdes deficiência em manutenção e infra-estrutura o que, consequentemente, reduziu o IAV para 0 (zero) $\mathrm{m}^{2} / \mathrm{hab}$., nas três Zonas. Neste sentido, caracteriza-se a necessidade existente de implantação e manutenção de Áreas Verdes no espaço intra-urbano de Paranavaí.

Palavras-chave: Área Verdes; Urbanização; Análise quali-quantitativa; IAV.

\footnotetext{
1. Graduada em Licenciatura em Geografia. FAFIPA, Mestranda em Geografia, UEM, Maringá/PR. Bolsista CNPq. Tel: (44) 3423-4383; e-mail: <helidafreire@hotmail.com>

2. Graduada em Turismo. PUC, Mestranda em Geografia UEM, Maringá/PR. Bolsista CAPES. Tel: (44) 3301-9133; e-mail: <zeteturismo@hotmail.com>

3. Graduado em Licenciatura em Geografia. Mestrando em Geografia, UEM, Maringá/PR. Bolsista CAPES. Tel: (44) 9133-8982; e-mail:<Edu_correia@hotmail.com>

${ }^{4}$. Prof. Dr. do Programa de Pós-Graduação da Universidade Estadual de Maringá, Maringá - PR. Tel. (44) 3261-8918; e-mail: <bldangelis@uem.br>
} 


\title{
INDEX OF GREEN AREAS FOR MACROZONE CONSOLIDATION IN PARANAVAÍ - PR
}

\begin{abstract}
The environmental quality and the quality of life are factors affected by the expansion process of urban areas. Vegetation has an important role in alleviating the adverse effect of urbanization, through its environmental, aesthetic and social, promoting improvements in both environmental condition as the population living on the city. The Research aimed to evaluate qualitatively and quantitatively the supply of Green Areas in three zones (1, 2 and 3) Paranavaí-PR. For that we used, at a first instance, the calculation of Green Area Index (IAV) considering the areas, regardless of the qualitative aspect. Subsequently was held a qualitative analysis of these areas and was recalculated the IAV. Through the first calculation, it was observed a reduced presence of green areas for the three zones, especially in Zones 13 and 0 (zero) $\mathrm{m}^{2} /$ hab. From the qualitative analysis, there was pointed deficiency in maintenance and infrastructure in all the green areas, which consequently reduced the IAV to 0 (zero) $\mathrm{m}^{2} /$ hab. in all the three zones. In this sense, it characterizes the need for establishing and maintaining green areas in the intra-urban area of Paranavaí.
\end{abstract}

Keywords: Urbanization; Green areas; Qualitative and quantitative analysis; IAV.

\section{INTRODUÇÃO}

No processo de expansão das áreas urbanas, nota-se que o homem alicerça o desenvolvimento e crescimento destas na transformação radical do espaço natural, o que altera as condições climáticas em diversas escalas (microclimas, topoclimas e mesoclimas) e, consequentemente, compromete a qualidade ambiental e de vida da população. Essas modificações ocorridas no âmbito das cidades incentivaram o surgimento de pesquisas que apontassem possíveis soluções para amenização dos efeitos prejudiciais da urbanização. Cavalheiro e Del Picchia (1992), Lombardo (1985), Romero (1988), Mascaró (2002), 
Monteiro (2003), Nucci (2001), Henke-Oliveira (1996) entre outros, realizam contribuições importantes, analisando as causas e as conseqüências das modificações nos espaços intraurbanos, e propondo alternativas que aliviassem os impactos negativos oriundos de tais modificações.

Cavalheiro e Del Picchia (1992) relatam que as cidades são basicamente constituídas, do ponto de vista físico, por espaços de interação urbana (rede rodoferroviária), espaços com construções (habitações, indústrias, comércio, hospitais, escolas, etc.) e espaços livres (praças, parques, águas superficiais, etc.). Para os autores é necessário que haja uma proporcionalidade ideal entre tais espaços, contudo, percebe-se que no recinto das cidades, os espaços livres são praticamente suprimidos.

Nucci (2008) ao realizar um trabalho de qualidade ambiental no distrito de Santa Cecília (Município de São Paulo), verificou que apenas 2,18\% da área total do distrito $\left(3.600 .000 \mathrm{~m}^{2}\right)$ eram ocupados pelo sistema de espaços livres de construção (sendo a maioria impermeabilizada), enquanto que os espaços construídos representaram $77,99 \%$, o que demonstra total desproporção entre os usos do solo urbano neste distrito.

Lombardo (1985) por sua vez, afirma que é necessária a realização de estudos que forneçam subsídios para um controle de ocupação do espaço urbano, fixando parâmetros físicos para um ambiente urbano mais compatível com a qualidade de vida. A autora, ao analisar a dinâmica dos fatores do tempo atmosférico na metrópole paulista, verificou que as temperaturas mais elevadas eram registradas em áreas de maior concentração de construções, sendo que em áreas livres e com vegetação, as temperaturas sofriam declínios acentuados. Dessa forma, aponta como indispensável, a elevação das proporções de cobertura vegetal no espaço urbano, para amenizar os impactos negativos da urbanização que vem afligindo a qualidade de vida da população, principalmente nos centros urbanos, onde se encontram níveis elevados de espaços construídos e de poluição atmosférica, devido ao intenso fluxo de veículos motorizados.

Mascaró (2002) discorre sobre algumas contribuições da vegetação para as condições ambientais urbanas, como a amenização da radiação solar na estação quente, modificação da temperatura e da umidade relativa do ar do recinto através do sombreamento que reduz a carga térmica recebida pelos edifícios, veículos e pedestres; modificação da velocidade e direção dos ventos; atuação como barreira acústica, entre outros.

Henke-Oliveira (1996) e Saydelles (2005) acrescentam que cobertura vegetal atua como interceptadora do escoamento superficial em dias de chuvas e através da proteção 
física e estabilizadora das raízes da arborização, da intercepção de gotas de chuva pela folhagem, impede a desestruturação física do horizonte superficial, conservando o solo e ao mesmo tempo, promove condições estruturais adequadas a este, através da matéria orgânica originária da cadeia de detritos. Além disso, a vegetação tem a capacidade de amenizar os elevados índices térmicos, visto que ela absorve a radiação solar e a libera para a atmosfera sob forma de calor latente contido na evapotranspiração, e não sob forma de calor sensível.

Romero (1988) contribui que a vegetação favorece a manutenção do ciclo oxigêniogás carbônico essencial à renovação do ar, o que é indispensável para assegurar a qualidade necessária à respiração humana.

Lombardo (1990) organiza essas e outras contribuições em quatro grupos: composição atmosférica, equilíbrio solo-clima-vegetação, níveis de ruídos e estético (Tabela $1)$.

Tabela 1. Contribuições da vegetação para melhoria do ambiente urbano

Table 1. Contributions of vegetation to improve the urban environment

\begin{tabular}{|c|c|}
\hline $\begin{array}{l}\text { COMPOSIÇÃO } \\
\text { ATMOSFÉRICA }\end{array}$ & $\begin{array}{l}\checkmark \quad \text { Ação purificadora por fixação de poeiras e } \\
\text { materiais residuais; } \\
\checkmark \quad \text { Ação purificadora por depuração bacteriana e } \\
\text { de outros microorganismos } \\
\checkmark \quad \text { Ação purificadora por reciclagem de gases } \\
\text { através de mecanismos fotossintéticos } \\
\checkmark \quad \text { Ação purificadora por fixação de gases tóxicos }\end{array}$ \\
\hline $\begin{array}{l}\text { EQUILÍBRIO SOLO- } \\
\text { CLIMA-VEGETAÇÃO }\end{array}$ & $\begin{array}{l}\checkmark \\
\text { Luminosidade e temperatura: a vegetação ao } \\
\text { filtrar a radiação solar suaviza as temperaturas } \\
\text { extremas } \\
\checkmark \quad \text { Umidade e temperatura: a vegetação contribui } \\
\text { para conservar a umidade dos solos, atenuando sua } \\
\text { temperatura } \\
\checkmark \quad \text { Redução na velocidade dos ventos } \\
\checkmark \quad \text { Mantém as propriedades do solo: } \\
\text { permeabilidade e fertilidade } \\
\checkmark \quad \text { Abrigo à fauna existente } \\
\checkmark \quad \text { Influência no balanço hídrico }\end{array}$ \\
\hline NÍVEIS DE RUÍDOS & $\begin{array}{l}\checkmark \quad \text { Amortecimento dos ruídos de fundo sonoro } \\
\text { contínuo e descontínuo de caráter estridente, } \\
\text { ocorrentes nas grandes cidades }\end{array}$ \\
\hline
\end{tabular}




\begin{tabular}{l|l}
\hline ESTÉTICO & $\checkmark \quad$ Quebra da monotonia da paisagem das \\
& cidades, causada pelos grandes complexos de \\
& edificações \\
& $\quad$ Valorização visual e ornamental do espaço \\
& urbano \\
& constituindo-se em um elemento de interação entre as \\
& atividades humanas e o meio ambiente
\end{tabular}

Fonte: Lombardo (1990) Source: Lombardo (1990)

Dessa forma, torna-se inegável a importância da vegetação nas cidades, pois é evidente o importante papel que esta pode desempenhar no espaço urbano, através de suas funções ambientais, estéticas e sociais.

Contudo, Nucci (2008) certifica que no processo de desenvolvimento das cidades, a vegetação, apesar de sua extrema importância para uma melhor ambiência e qualidade de vida urbana, tem sido negligenciada. Diferentemente de outros recursos físicos da cidade, a cobertura vegetal não é vista como uma necessidade óbvia no ambiente urbano, e, na maioria das situações, tem suas funções reduzidas a valores sentimentais e estéticos.

Nesse sentido, torna-se de grande importância o incentivo de todas as possibilidades de aumento da cobertura vegetal nas áreas urbanas, uma vez que estas se encontram cada vez mais inóspitas e pouco acolhedoras a qualquer forma de vida.

A criação de Áreas Verdes é uma das alternativas para manter quantidades significativas de vegetação nas cidades. Toledo et al. (2009) enfatizam que a criação de Áreas Verdes como parques e praças, na zona urbana dos municípios, amplia o Índice de Área Verde per capita, auxiliando no aumento da qualidade de vida da população.

Entretanto, ao se tratar de Áreas Verdes, é notória a dificuldade que se tem ao tentar definir o termo. A falta de esclarecimento sobre este pode ser compreendida pela ausência de arborização nos espaços das cidades medievais e renascentistas no decorrer da história, sendo que, somente a partir do século XIX, com o advento da Revolução Industrial, na Inglaterra, França, Alemanha, Estados Unidos, é que este assunto começa a ser cogitado, com frequência, devido às preocupações das autoridades com a estética e com os problemas sanitários (TOLEDO; SANTOS, 2008).

Barbosa (2005) afirma que esta dificuldade assume proporções maiores, devido à existência de termos análogos e igualmente abrangentes como áreas livres, espaços abertos, sistemas de lazer, entre outros. 
No entanto, Lima et al. (1994), em um trabalho que objetivou levantar a polêmica sobre uma conceituação mais globalizante, através de consultas a órgãos de pesquisa, ensino e planejamento urbano, da Regional Sudeste da Sociedade Brasileira de Arborização Urbana e profissionais da área; discutiram a definição de alguns termos técnicos, como arborização urbana, Áreas Verdes, parques e praças. Para os autores tais termos têm a seguinte definição:

- Área Verde: onde há o predomínio de vegetação arbórea; engloba as praças, os jardins públicos e os parques urbanos. Os canteiros centrais e trevos de vias públicas, que tem apenas funções estética e ecológica, devem, também, conceituar-se como Área Verde. Entretanto, as árvores que acompanham o leito das vias públicas, não devem ser consideradas como tal (...).

- Parque Urbano: é uma Área Verde, com função ecológica, estética e de lazer, entretanto com uma extensão maior que as chamadas Praças e Jardins Públicos.

- Praça: como Área Verde, tem a função principal de lazer. Uma praça, inclusive, pode não ser uma Área Verde, quando não tem vegetação e é impermeabilizada (...); no caso de ter vegetação é considerada Jardim (...).

- Arborização Urbana: diz respeito aos elementos vegetais de porte arbóreo, dentro da urbe, tais como árvores e outras. Nesse enfoque, as árvores plantadas em calçadas, fazem parte da Arborização Urbana, porém, não integram o Sistema de Áreas Verdes (LIMA et al. 1994, p.549).

Para Buccheri-Filho e Nucci (2006) canteiros centrais e trevos de vias públicas não podem ser considerados como Áreas Verdes, mas sim verde de acompanhamento viário, que com as calçadas pertencem à categoria de espaços construídos ou espaços de integração urbana. Os autores acrescentam que as áreas verdes devem satisfazer três objetivos principais: ecológico-ambiental, estético e de lazer. Além disso, a vegetação deve ser o elemento fundamental e, juntamente com o solo permeável ocupar, no mínimo, 70\% da área.

Contudo, apesar da necessidade de estudos voltados aos problemas conceituais relativos às Áreas Verdes, deve-se destacar a importância daqueles que procuram conhecer a dinâmica destas nas cidades.

Costa e Ferreira (2009) afirmam que um indicador de grande relevância para informar a presença ou ausência dessas áreas é o Índice de Áreas Verdes (IAV). Tal índice, segundo Fontes (2008), é a relação entre valor de área caracterizada como Área Verde e população residente. Para Henke-Oliveira (2001) o IAV deve ser calculado a partir das 
Áreas Verdes públicas de acesso coletivo, ou seja, as praças, jardins e bosques urbanos, excluídos os canteiros centrais de ruas e avenidas.

Cavalheiro e de Del Picchia (1992, p.32) ressaltam que:

Os índices existentes não são receitas a serem seguidas, antes eles servem como apoio científico para o planejamento, já que se deve lembrar que a ciência se preocupa com uma acumulação de conhecimento da humanidade e que se deve ter apoio do que já foi gerado. Não se deve, entretanto, esquecer que o planejamento deve possibilitar um contínuo replanejamento, para que se contemplem mudanças nas aspirações da sociedade.

Os autores supracitados salientam ainda que, índice mínimo de $12 \mathrm{~m}^{2}$ de área verde/habitante, supostamente estabelecido pela ONU ou a OMS, ou a FAO, na verdade não é reconhecido por essas organizações.

Fontes (2008), Toledo et al. (2009), Harder et al. (2006), ressaltam que deve-se ter como uma referência em termos de qualidade urbana relacionada à oferta de espaços livres, a "Carta a Londrina e Ibiporã" (SBAU, 1996) na qual se propõe como índice mínimo para áreas verdes públicas destinadas à recreação o valor de $15 \mathrm{~m}^{2} /$ habitante.

Nucci (2008) ao tratar da avaliação de Áreas Verdes, informa que esta análise não deve ater-se apenas ao aspecto quantitativo, mas estender-se para o qualitativo, pois muitas vezes tem-se a área à disposição, mas sem condições de uso. O autor acrescenta que após a quantificação das Áreas Verdes, dever-se-ia recalcular o Índice de Áreas Verdes, indicando a quantidade delas utilizáveis pela comunidade de acordo com suas qualificações.

Dessa forma, este artigo tem a perspectiva de avaliar os aspectos quali-quantitativos das Áreas Verdes existentes em três Zonas (1, 2 e 3) situadas na Macrozona de Consolidação de Paranavaí-PR e computar o Índice de Áreas Verdes para estas áreas, na intenção de compreender a realidade destes espaços, oferecer subsídios para a realização de um planejamento urbano e ambiental condizente com a realidade e a necessidade desta cidade.

\section{MATERIAIS E MÉTODOS}

Paranavaí é uma cidade de porte médio, localizada na região Noroeste do Paraná (Figura 1), com altitude média de 503 metros e território de $1.202,151 \mathrm{~km}^{2}$. Surgiu de um 
processo de ocupação da porção norte do território paranaense, que se iniciou nos anos 20, devido à expansão da cafeicultura paulista (IPARDES, 2011).

Estimativas do Instituto Brasileiro de Geografia e Estatística - IBGE, informam que em 1950 o município contava com uma população de 25.520 habitantes, sendo que desse total $92,7 \%$ residia na área rural e 7,3\% na área urbana (ALCÂNTRA, 1987). Atualmente o município possui uma população de 81.590 sendo que, aproximadamente, 95,2\% reside na área urbana e 4,8\% na área rural, atingindo um grau de urbanização de 95,27\% (IPARDES, 2011).

O clima do município, segundo Köppen, é do tipo Cfa, Subtropical Úmido Mesotérmico, de verões quentes, zona tropical marginal, com precipitação regular todos os meses, sem estações secas. Porém, devido ao intenso desmatamento, vem ocorrendo variações no clima, causando perturbação do limite entre as zonas climáticas, com alterações do coeficiente de variação das precipitações. Paranavaí está inserido na região da Floresta Estacional Semidecidual, hoje muito descaracterizada pelas constantes ações antrópicas que sofreu ao longo dos anos, obedecendo a dinâmica do processo de urbanização, ficando apenas áreas residuais correspondente a um Bosque Municipal, um Parque na região do Córrego Xaxim e algumas áreas de Reserva Florestal Legal de propriedades particulares, localizados na periferia da cidade ou em locais de difícil acesso (STIPP, 2006). 
Figura 1. Localização do Município de Paranavaí-PR

Figure 1. Location of Paranavaí-PR Municipality
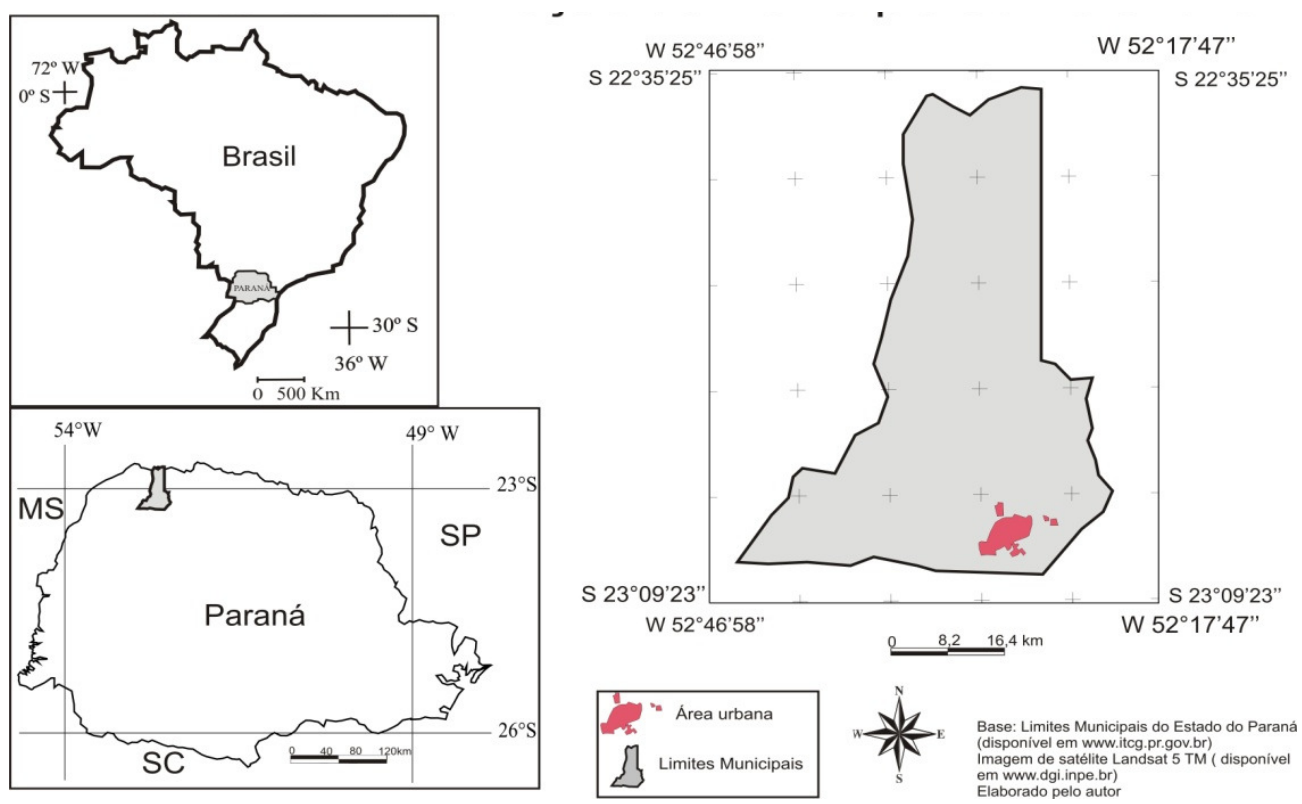

O município é dividido em Área Urbana e Área Rural. Estas áreas foram subdivididas com base em um macrozoneamento, cuja finalidade é fixar as regras fundamentais de ordenamento do território e tem como objetivo definir diretrizes para o ordenamento territorial de forma a atender os princípios, os objetivos gerais, as políticas gerais e as estratégias do Plano Diretor (Câmara Municipal de Paranavaí, 2011, Lei № 3.297/2008).

De acordo com o Plano diretor Municipal (Art. 82), a área urbana é definida pela composição dos limites das seguintes Macrozonas:

I - Macrozona Urbana de Consolidação;

II - Macrozona Urbana de Qualificação;

III - Macrozona Urbana de Expansão Orientada;

IV - Macrozona Urbana de Indústrias e Serviços de Grande Porte;

A unidade de estudo deste artigo compreende as Zonas 1, 2 e 3, ambas inseridas na Macrozona Urbana de Consolidação, a parte mais antiga da sede urbana, de maior adensamento populacional e de concentração comercial e serviços de pequeno porte (Art. 90).

Para obter a quantidade de áreas verdes, principiou-se por localizar na área de estudo, locais que, num primeiro momento, foram definidos como espaços possíveis de serem áreas verdes, como praças e parques públicos. Para tanto, realizou-se pesquisas na 
Prefeitura Municipal de Paranavaí junto à Secretaria de Planejamento Urbano e do Meio Ambiente e na Câmara Municipal.

Após esse primeiro procedimento realizou-se pesquisa in loco para verificar se tais áreas enquadravam-se na classificação de áreas verdes proposta por Lima et al. (1994), excetuando-se canteiros centrais e trevos de vias públicas, áreas que não cumprem a função de lazer e com permeabilidade inferior a 70\%, conforme Henke-Oliveira, 2001; Nucci et al., 2003; Buccheri-Filho; Nucci, 2006.

Com o total de áreas verdes definido, realizou-se uma análise qualitativa de tais espaços, utilizando a metodologia proposta por Harder (2002), onde se faz o cálculo do índice de áreas verdes utilizáveis. Para tanto, tais áreas foram classificadas em totalmente utilizáveis (1), parcialmente utilizáveis (2) e sem condições de uso (3), sendo consideradas totalmente utilizáveis aquelas com equipamentos e infraestrutura em bom estado de conservação; parcialmente utilizáveis aquelas com equipamentos e infraestrutura com estado razoável de conservação; e sem condições de uso, ausência de equipamentos e infraestrutura.

Os dados censitários da área foram recolhidos no Instituto Brasileiro de Geografia e Estatística (IBGE) baseado no resultado do censo de 2000.

Para encontrar a quantidade de permeabilização, subtraiu-se o valor total de área livre permeável da área total do logradouro. Através de uma regra de três simples, calculouse a porcentagem de permeabilidade.

A computação do Índice de Áreas Verdes (IAV) está baseada no cálculo mais utilizado, onde se divide somatório destas áreas em metros quadrados $\left(\mathrm{m}^{2}\right)$ pela população da área estudada.

\section{RESULTADOS E DISCUSSÃO}

Constatou-se em Paranavaí a existência de treze praças públicas e um parque municipal (Figura 2 e Tabela 2), que num primeiro momento foram definidos como espaços possíveis de serem áreas verdes, baseado na classificação proposta neste trabalho. 
Figura 2. Distribuição de praças e parques por Zona

Figure 2. Distribution of squares and parks by area

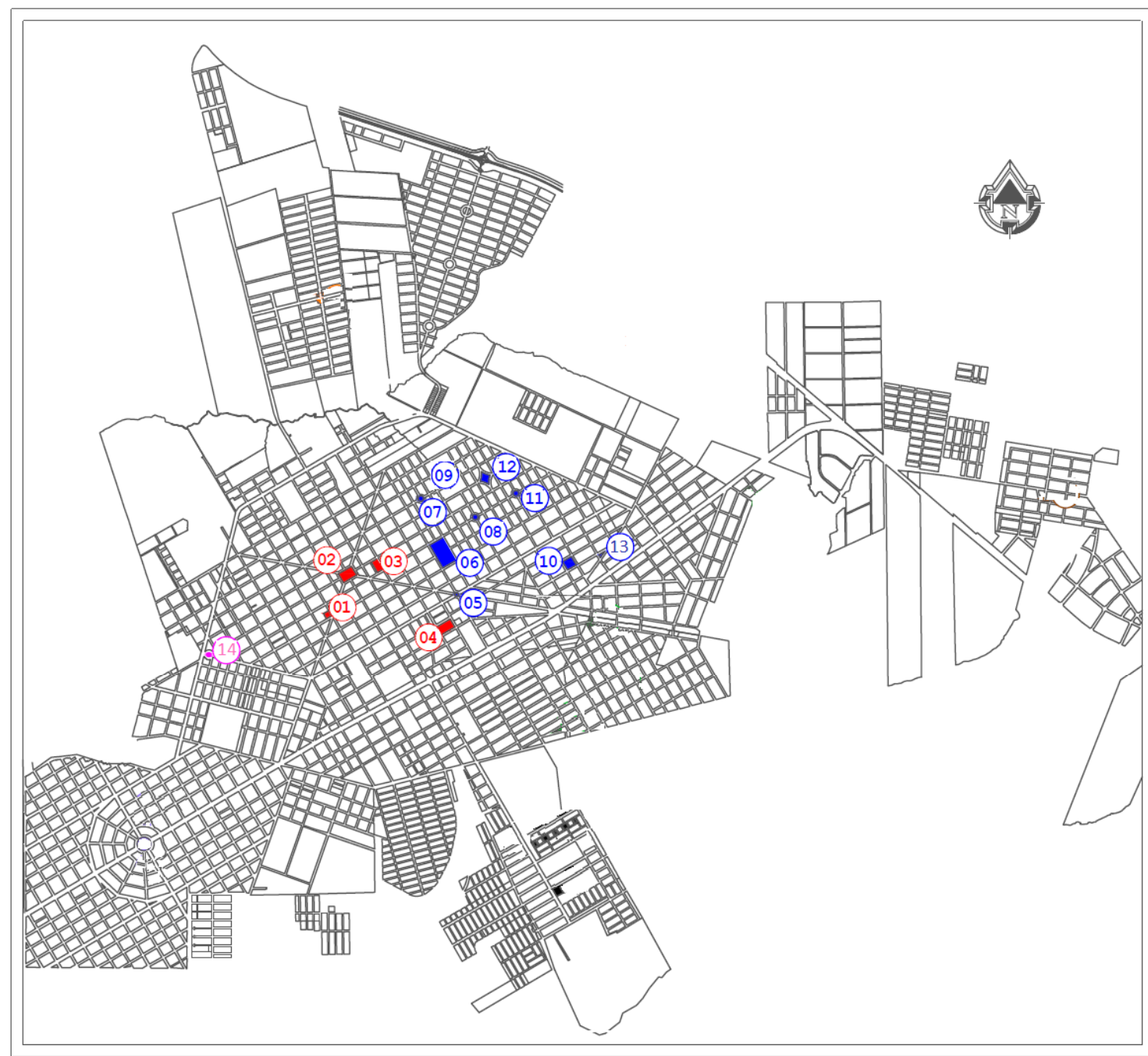

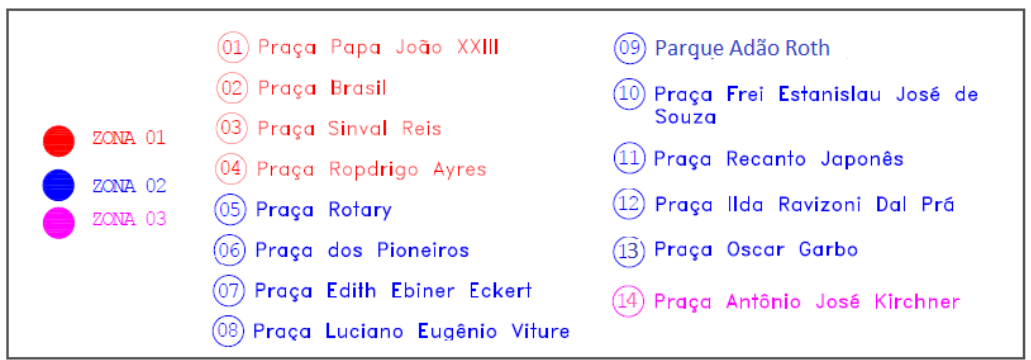

Fonte: Prefeitura Municipal de Paranavaí. (Org.: FREIRE, 2011) Source: City Hall Paranavai. (Org.: FREIRE, 2011) 
Tabela 2. Distribuição das praças e parques por Zona e suas áreas totais

Table 2. Distribution of squares and parks in their Zone and total areas

\begin{tabular}{l|l|l}
\hline Praça/ Parque & Área total (m²) & Zona \\
\hline Papa João XXIII & 1.584 & 1 \\
\hline Brasil & 9.115 & 1 \\
\hline Sinval Reis & 5.300 & 1 \\
\hline Rodrigo Ayres & 8.920 & 1 \\
\hline Rotary & 820 & 2 \\
\hline Dos Pioneiros & 23.000 & 2 \\
\hline Edith Ebiner Eckert & 1.662 & 2 \\
\hline Luciano Eugênio Viture & 1.662 & 2 \\
\hline Parque Adão Roth & 52.000 & 2 \\
\hline Frei Estanislau José de Souza & 5.910 & 2 \\
\hline Recanto Japonês & 1.735 & 2 \\
\hline Oscar Garbo & 780 & 2 \\
\hline Ida Ravizone Dal-Prá & 4.963 & 2 \\
\hline Antônio José Kirchner & 804 & 3 \\
\hline
\end{tabular}

Fonte:

Secretaria do Meio Ambiente, 2010 (Org.: FREIRE, 2011). Source: Secretary of the Environment, 2010 (Org.: FREIRE, 2011).

De acordo com o Plano Diretor de Paranavaí (Câmara Municipal de Paranavaí, 2011), a Zona 1 está inserida na porção central de Paranavaí, área de concentração comercial e de serviços diversos, densamente construída, com sua localização condicionada pelos principais fluxos de veículos.

As Zonas 2 e 3 são áreas predominantemente residenciais, porém de nível econômico diferenciado, sendo que a primeira destaca-se por excelentes padrões de residências, e nível sócio-econômico alto, e a segunda apresenta casas sociais e nível sócio-econômico médio a baixo. 


\section{Análise quantitativa}

Para definir tais espaços como áreas verdes, realizou-se um processo verificação, dividido em etapas, quais sejam: 1) análise da existência de permeabilidade mínima de 70\%; 2) análise de predominância de espécies arbóreas; 3) análise da função de lazer.

Este processo de verificação foi empregado somente nas praças públicas de Paranavaí, tendo em vista que, foi possível constatar que o Parque Municipal atende os três requisitos supracitados, sem a necessidade de um levantamento específico.

Permeabilidade

Das treze praças, cinco apresentaram a permeabilidade mínima de $70 \%$, quais sejam: Praça Rotary (100\%), Praça Edith Ebiner Eckert (84\%), Praça Recanto Japonês (85\%), Praça Ida Ravizone Dal-Prá (100\%) e Praça Oscar Garbo (72\%).

Predominância de espécies arbóreas

Não basta uma área ter o mínimo de permeabilidade e não possuir uma predominância de árvores em seu espaço, pois, mesmo que um local apresente um bom índice de permeabilização, mas seja desprovido dos benefícios provindos de espécies arbóreas, não exercerá a função de uma área verde, e vice-versa.

Neste levantamento encontraram-se praças com total ausência de árvores em seu recinto. É o caso da Praça Ida Ravizone Dal-Prá que apesar de ter $100 \%$ de área permeável, é um espaço com ausência de vegetação de porte arbóreo e totalmente desprovido de qualquer infraestrutura, onde viceja o mato.

Em outras praças, apesar de existir arborização, a vegetação rasteira é a que predomina. Nessa condição encontram-se as praças Rotary, Edith Ebiner Eckert e Recanto Japonês.

Assim, das cinco praças públicas que possuem uma quantidade igual ou superior à 70\% de área permeável, apenas uma apresentou uma predominância vegetal arbórea, qual seja, Praça Oscar Garbo. 
Função Lazer

A função de áreas verdes não deve limitar-se a benefícios ambientais, mas antes deve estender-se aos aspectos sociais. O lazer é uma necessidade básica do ser humano e por isso se constitui em um dos direitos sociais do cidadão previsto no artigo 6ำ da Constituição Federal.

Nesta análise constatou-se que a Praça Oscar Garbo possui aptidão para exercer a função lazer, uma vez que, apresenta em seu recinto equipamentos e/ou estruturas voltadas para esta função.

Dessa forma, foram classificadas como áreas verdes a Praça Oscar Garbo e o Parque Adão Roth, ambos localizados na Zona 2, que conta com uma população aproximada de 8.456 habitantes, resultando em um Índice de Áreas Verdes de 6,2 m²/hab para esta Zona. A ausência de espaços que se enquadrassem na conceituação de Áreas Verdes utilizada neste estudo, resultou no IAV 0 (zero) $\mathrm{m}^{2} / \mathrm{hab}$. para as Zonas 1 e 3 , demonstrando total desproporção em oferta de Áreas Verdes para as três Zonas.

Entretanto, vale ressaltar que a arborização urbana é um bem público, portanto deve ter equitativa distribuição e acessibilidade para a população, uma vez que, a Lei Orgânica do município (Câmara Municipal de Paranavaí, 2011; Art. 111; II; III; V) alega que a política de desenvolvimento urbano, executada pelo Poder Público Municipal deve procurar assegurar "o acesso de todos os seus cidadãos às condições adequadas de moradia, transporte público, saneamento básico, infra-estrutura viária, saúde, educação, esporte e lazer e às oportunidades econômicas existentes no Município; a segurança e a proteção do patrimônio paisagístico, arquitetônico, cultural e histórico; a qualidade estética e referencial da paisagem natural agregada pela ação humana" (grifo nosso).

\section{Análise qualitativa}

A análise qualitativa consistiu na avaliação dos equipamentos e/ou estruturas presentes nas duas áreas verdes, conforme metodologia proposta por Harder (2002). 


\section{Praça Oscar Garbo}

Através da Lei nº 2.404/2003 (Câmara Municipal de Paranavaí, 2011), a praça em tela recebeu o referido topônimo. De conformação triangular, encontra-se situada em zona residencial e apresenta caminhos feitos de concreto somente em sua parte externa, não tendo ligação com o seu centro, desprovido de qualquer tipo de revestimento (Figura 3). A iluminação é rebaixada, sem contato com as copas das árvores e bem distribuída. Possui lixeiras bem antigas e danificadas. Até o início deste ano havia em seu espaço um sanitário em condições impróprias para uso, devido às péssimas condições que se encontrava, além de um barracão (há muito tempo desativado) onde os moradores do local, antigamente, jogavam partidas de bocha. O barracão foi demolido e em seu lugar inseriu-se uma Academia para Terceira Idade (ATI). O sanitário também foi retirado do local, porém, nada foi inserido em seu lugar. A ausência de segurança e de manutenção são fatores que a torna uma área de repulsão social. Apenas um grupo de homens idosos há tempos freqüenta fielmente a praça para jogar partidas de baralho nas mesas de concreto que há no local, o que a tornou conhecida popularmente como "Praça do Saco Murcho".

Figura 3. Praça Oscar Garbo

Figure 3. Square Oscar Garbo

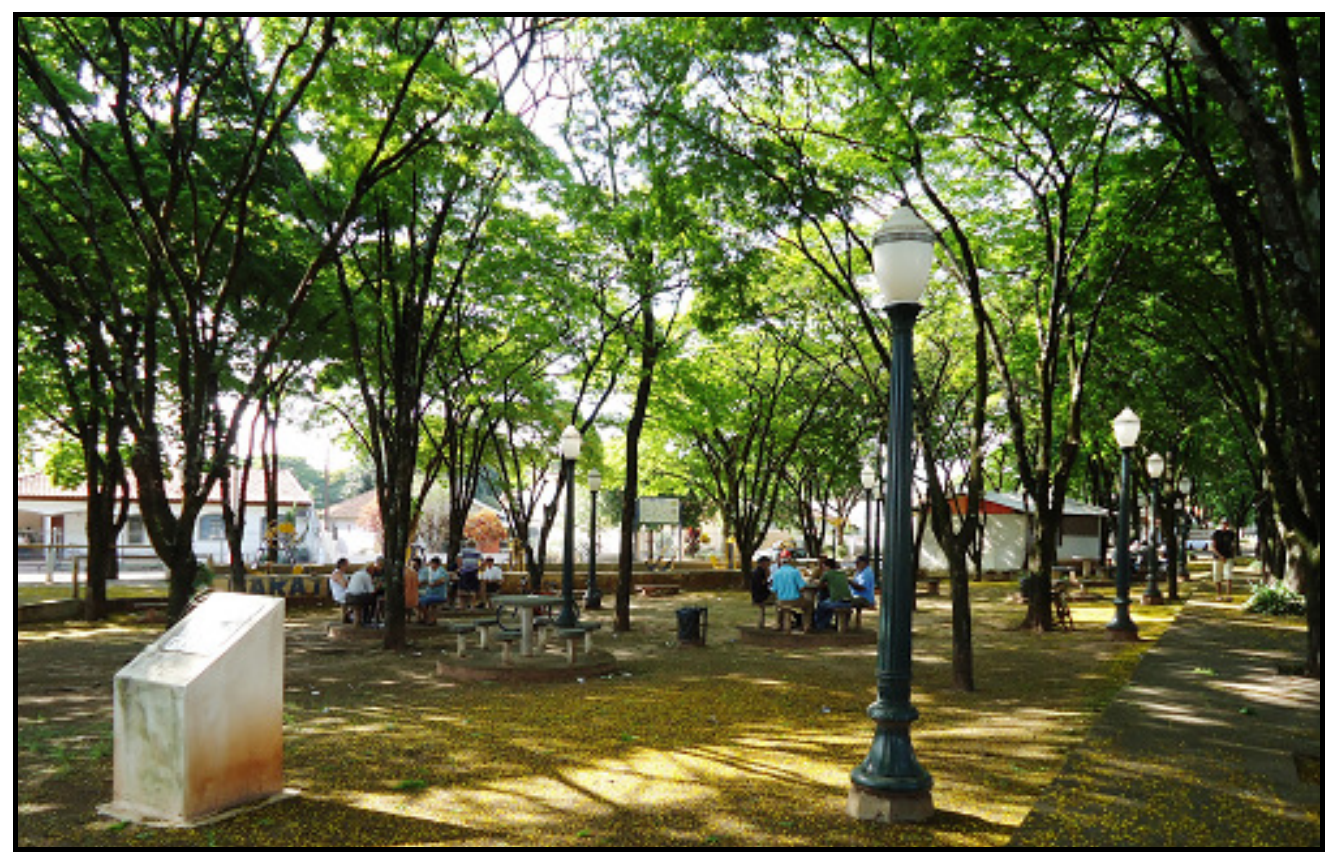


Parque Adão Roth

Anteriormente denominado Parque Ouro Branco, o logradouro em questão recebeu o topônimo Adão Roth através da Lei nº 2564 de 31 de dezembro de 2004 (Câmara Municipal de Paranavaí, 2011), contudo, atualmente continua sendo referenciado popularmente pela antiga denominação. Nele encontra-se a casa do ex-prefeito Ulisses Bandeira, que serve como Escritório Regional do Instituto Brasileiro de Meio Ambiente (IBAMA).

As primeiras obras começaram a serem executadas no ano de 1998, com a construção de quiosques, sanitários, canchas de bocha, canchas de futebol e vôlei de areia e alguns brinquedos em eucalipto tratado. Estas obras foram realizadas pelo Governo do Estado em parceria com a Prefeitura de Paranavaí. Em 2003, construiu-se uma pista de caminhada, reformou-se os sanitários, a iluminação foi inserida, plantaram-se árvores no entorno da pista e grama, fez-se o isolamento da mata ciliar e curvas de níveis no interior do parque (Secretaria Municipal de Meio Ambiente, 2011).

Em 2004 foi realizada a execução de galerias de águas pluviais e o parque passou por um processo de revitalização. Atualmente encontra-se em um estado total de abandono, onde viceja o mato. Os equipamentos e/ou estruturas, de uma forma geral, apresentam-se em estado precário. Os brinquedos e quiosques estão danificados, a pista de caminhada além de estreita, disputa espaço com o mato rasteiro, os sanitários encontram-se imundos e vandalizados, a cancha de bocha depredada, está inutilizável.

Devido à falta de segurança e a constante prática de atividades ilícitas em seu recinto, tornou-se mais uma das áreas de repulsão social da cidade, não cumprindo, efetivamente, sua função social (Figura 4). 
Figura 4. Parque Adão Roth

Figure 4. Park Adão Roth

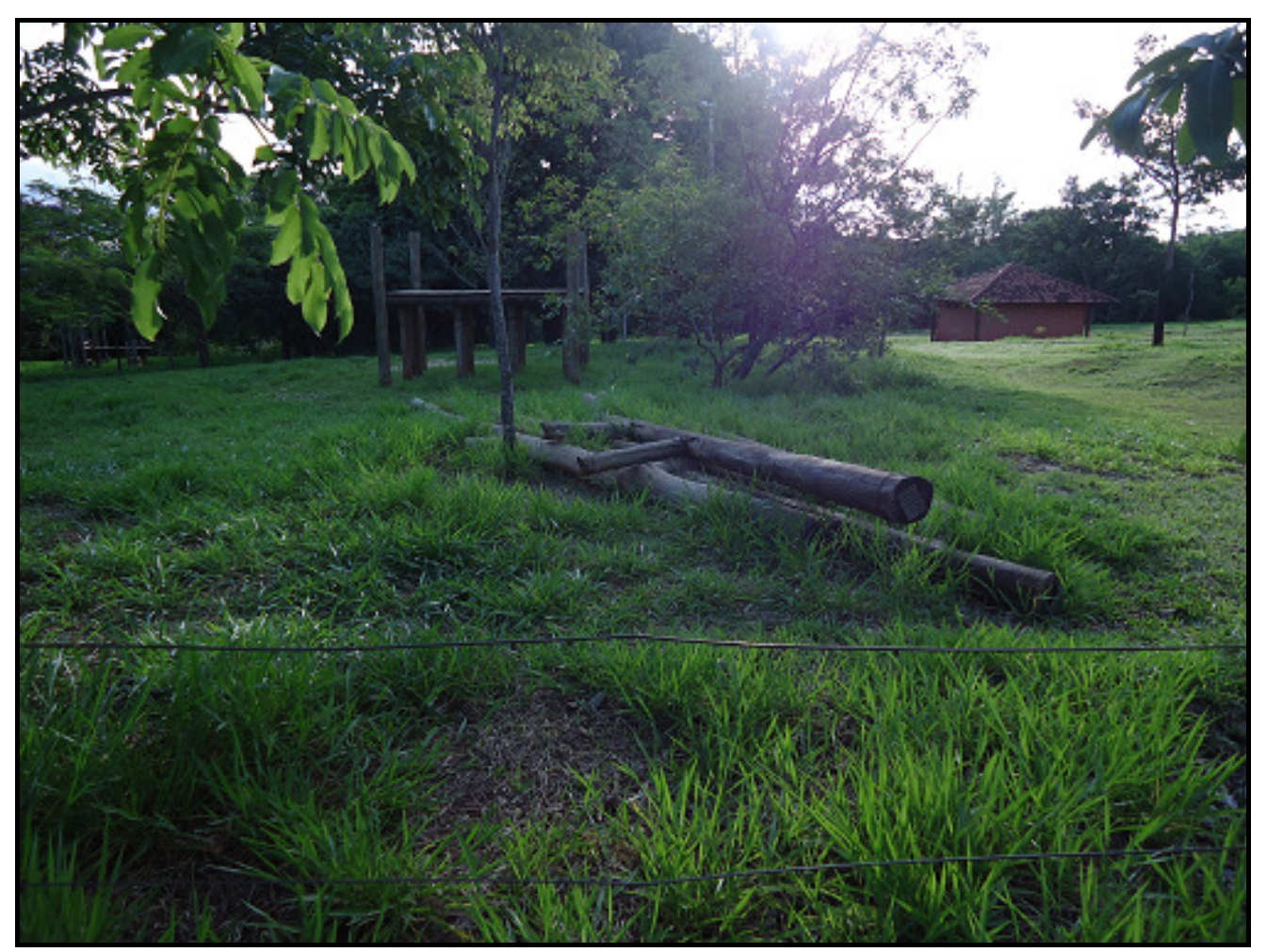

Mediante esta análise constata-se que nenhuma das duas áreas verdes, foi classificada como totalmente utilizável, uma vez que, ambas apresentam sérios problemas em manutenção de estruturas e/ou equipamentos que associado à ausência de segurança, prejudica que tais áreas exerçam suas funções sociais efetivamente. Assim, o IAV encontrado para as três Zonas após a avaliação qualitativa foi de 0 (zero) m²/hab.

Vale ressaltar que um dos fatores determinantes para este resultado foi a falta de segurança nas áreas analisadas, uma vez que os equipamentos e/ou estruturas são vítimas constantes de ações vandálicas e a prática de atividades ilícitas impede a ida da população a estes espaços.

Henrique (2006) ressalta que a deterioração de praças e parques através do abandono e da falta de manutenção, faz com que a população passe a enxergá-los como sinônimos de lugares perigosos e violentos, o que acaba reprimindo a ida desta em tais locais. 
Além disso, o baixo IAV encontrado para cada uma das Zonas, associado ao acelerado processo de urbanização, sem um planejamento que assegure a manutenção e multiplicação de Áreas Verdes, acaba influenciando diretamente nas condições do ambiente e, consequentemente, na qualidade de vida da população paranavaiense.

\section{CONCLUSÕES}

Nas três Zonas analisadas, o Índice de Áreas Verdes ficou abaixo do mínimo de $15 \mathrm{~m}^{2}$ per capita, acentuadamente nas Zonas 1 e 3 que, de acordo com a análise quantitativa, apresentaram um índice muito aquém do mínimo recomendado. Tal situação evidencia a ausência das Áreas Verdes na cidade, mesmo diante dos diversos benefícios proporcionados por elas na ambiência e na qualidade de vida citadina, demonstrando que a relação existente entre o urbano e a vegetação é inversamente proporcional, pois, à medida que um se expande, diminui-se radicalmente o outro.

Através do levantamento qualitativo, constatou-se um quadro mais grave, uma vez que, o IAV das três Zonas foi reduzido para 0 (zero) $\mathrm{m}^{2} /$ hab., após a análise das condições de uso de tais espaços, pois, em todos foram verificados danos diversos aos equipamentos e infraestruturas, descaracterizando-os como totalmente utilizáveis.

Dessa forma, torna-se necessário enfatizar a importância das Áreas Verdes em termos das diversas funções desempenhadas por elas, no intuito de buscar a compreensão e a valorização de tais benefícios, além de incentivar a criação de mecanismos que permitam manter e multiplicar essas áreas nas cidades.

É importante ressaltar ainda que, a distribuição espacial e a acessibilidade destes espaços devem ocorrer de maneira equitativa, atendendo a necessidade de todos e não apenas de uma parcela privilegiada da população. Portanto, além da evidente necessidade de manutenção, faz-se necessário também, uma implantação mais igualitária destas áreas na cidade de Paranavaí. 


\section{REFERÊNCIAS}

ALCANTRA, J.C. Política Local - Um estudo de caso: Paranavaí, 1952 - 1982. Tese (Mestrado). UNICAMP, 1987; p. 291.

BARBOSA, R. V. R. Áreas Verdes e Qualidade Térmica em Ambientes Urbanos: estudo em microclimas de Maceió (AL), 2005. Dissertação (Mestrado em Ciências da Engenharia Ambiental) - Escola de Engenharia de São Carlos, Universidade de São Paulo, São Carlos, 2005.

BRASIL. Constituição (1988). Constituição da República Federativa do Brasil. Brasília, DF, Senado, 1998.

BUCCHERI-FILHO, A.T.; NUCCI, J. C. Espaços livres, áreas verdes e cobertura vegetal no bairro Alto da XV, Curitiba/PR. In: Revista do Departamento de Geografia, 2006, n. 18, p. 48-59.

CAVAlHEIRO, F.; DEL PICCHIA, P. C. D. Áreas Verdes: Conceitos, Objetivos e Diretrizes para o Planejamento. In: $1^{\circ}$ Congresso Brasileiro sobre Arborização Urbana e $4^{\circ}$ Encontro Nacional Sobre Arborização Urbana, Vitória/ES, 1992. Anais. p. 29-38.

COSTA, R. G.S.; FERREIRA, C. C. M. Análise do Índice de Áreas Verdes (IAV) na área central da cidade de Juiz de Fora, MG. In: Revista Sociedade Brasileira de Arborização Urbana. (REVSBAU), Piracicaba - SP, v.4, n.1, p.39-57, 2009.

FONTES, N. Indicadores, índices e padrões relativos a sistemas de espaços livres. In: 1 Simpósio de Pós-graduação em Geografia do Estado de São Paulo- SIMPGEO-SP, Rio Claro, 2008.

HARDER, I. C. F. Inventário Quali-Quantitativo da Arborização e Infra-Estrutura das Praças da cidade de Vinhedo (SP). Dissertação (Mestrado). Escola Superior de Agricultura Luiz de Queiroz. Piracicaba, SP, 2002. 
HARDER, I. C. F.; RIBEIRO, R. C. S.; TAVARES, A. R. Índices de área verde e cobertura vegetal para as praças do município de vinhedo, SP. In: Revista Árvore. Viçosa - MG, v. 30, n.2, p. $277-282,2006$.

HENKE-OLIVEIRA, C. Planejamento ambiental na Cidade de São Carlos (SP) com ênfase nas áreas públicas e áreas verdes: diagnóstico e propostas. Dissertação (Mestrado em Ecologia Recursos Naturais), Centro de Ciências Biológicas e da Saúde/UFSCar, São Carlos - SP, 1996.

HENKE-OLIVEIRA, C. Análise de padrões e processos no uso do solo, vegetação, crescimento e adensamento urbano. Estudo de caso: município de Luiz Antônio (SP). Tese (Doutorado em Ciências). Universidade Federal de São Carlos. São Carlos, São Paulo, 2001.

HENRIQUE, W. A cidade e a natureza: a apropriação, a valorização e a sofisticação da natureza nos empreendimentos imobiliários de alto padrão em São Paulo. In Revista GEOUSP - Espaço e Tempo. São Paulo, n. 20, p. 65 - 77, 2006.

IPARDES. Instituto Paranaense de Desenvolvimento Econômico e Social. Caderno Estatístico do município de Paranavaí. Disponível em : < http://www.ipardes.gov.br/ cadernos/Montapdf.php?Municipio=87700\&btOk=ok>. Acesso em: 15/08/2011.

LIMA, A.M.L.P.; CAVALHEIRO, F.; NUCCI, J.C.; SOUZA, M.A.L.B.; FIALHO, N.O ; DEL PICCHIA, P.C.D. Problemas de utilização na Conceituação de termos como espaços livres, áreas verdes e correlatos. In: II Congresso Brasileiro sobre Arborização Urbana, 2, São Luiz/MA, 1994. Anais. p. 539-553.

LOMBARDO, M. A. Ilha de Calor nas metrópoles: o exemplo de São Paulo. São Paulo, HUCITEC, 1985. 244 p.

LOMBARDO, M. A. Vegetação e clima. In: Encontro Nacional sobre Arborização Urbana, 3, 1990, Curitiba. Anais. Curitiba: Impresso na Fundação de Pesquisas Florestais do Paraná, 1990. p. 1 - 13. 
MASCARÓ, L. E. A. R de; Mascaró, J. L. Vegetação urbana. Porto Alegre: L. Mascaró, J. Mascaró, 2002. 242p.

MONTEIRO, C. A. F. Teoria e Clima Urbano. São Paulo: IGEO/USP, 2003. 192p.

NUCCI, J. C. Qualidade ambiental \& adensamento urbano: um estudo de ecologia e planejamento da paisagem aplicado ao distrito de Santa Cecília (MSP). São Paulo: Humanitas, 2001. 142p.

NUCCI, J. C.; WESTPHALEN, L. A.; BUCCHERI-FILHO, A. T.; NEVES D. L.; OLIVEIRA,F. A. H. D.; KROKER, R.Cobertura vegetal no bairro de Curitiba/PR. Artigo publicado na Revista GEOUERJ, número especial - Rio de Janeiro, 2003 (CD ROM).

CÂMARA MUNICIPAL DE PARANAVAÍ.Lei Orgânica, de 04 de abril de 1990. Paranavaí, 1990. Disponível em: < http://www.leismunicipais.com.br/cgilocal/orglaw.pl?city=Paranava\%ED\&state=pr>. Acesso em: 30/08/2011.

Lei Municipal no 2.404, de 07 de abril de 2003. Denominação de Praça Pública. Disponível em: <http://www.cmparanavai.pr.gov.br/index.php?sessao= c2e8251608ltc2> Acesso em: 30/08/2011.

Lei Municipal no 2.564, de 31 de dezembro de 2004. Denominação de Denominação do Parque Ouro Branco Adão Roth. Disponível em: <http://www.cmparanavai.pr.gov.br/index.php?sessao= c2e8251608ltc2> Acesso em: $30 / 08 / 2011$.

- Lei Municipal no 3.300, de 20 de novembro de 2008. Dispõe sobre 0 Parcelamento do Solo no Município de Paranavaí, Condomínios Horizontais e dá outras providências. Disponível em: <http://www.cmparanavai.pr.gov.br/index.php? sessao=c2e8251608ltc2> Acesso em: 30/08/2011. 
Lei Municipal no 8, de novembro de 2008. Dispõe sobre o Plano Diretor e define princípios, políticas, estratégias e instrumentos para o desenvolvimento municipal e para o cumprimento da função social da propriedade no Município de Paranavaí e dá outras providências. Disponível em: <http://www.cmparanavai.pr.gov.br/index.php?sessao=c2e8251608ltc2> Acesso em: $30 / 08 / 2011$.

ROMERO, M. A. B. Princípios bioclimáticos para o desenho urbano. São Paulo: Projeto, 1988. $128 p$.

SAYDELLES, A. P. Estudo do campo térmico e das ilhas de calor urbano em Santa Maria-RS. Dissertação (mestrado). Universidade Federal de Santa Maria, RS. 2005.

SECRETARIA MUNICIPAL DE MEIO AMBIENTE. Histórico Parque Adão Roth. Paranavaí, 2011.

SOCIEDADE BRASILEIRA DE ARBORIZAÇÃO URBANA - SBAU. "Carta a Londrina e Ibiporã". Boletim Informativo, v.3 , n.5, p.3, 1996.

STIPP, M. E. F. A ocupação do solo e a problemática da arenização e voçorocamento no município de Paranavaí. São Paulo, 2006. Dissertação (Mestrado) - Faculdade de Filosofia, Letras e Ciências Humanas da Universidade de São Paulo.

TOLEDO, F. S.; SANTOS, D. G. Espaços livres de construção. In: Revista Sociedade Brasileira de Arborização Urbana. (REVSBAU), Piracicaba - SP, v.3, n.1, p.73-91, 2008.

TOLEDO, F. S.; MAZZEI, K.; SANTOS, D. G. Um índice de áreas verdes (IAV) na cidade de Uberlândia/MG. In: Revista Sociedade Brasileira de Arborização Urbana. (REVSBAU), Piracicaba - SP, v.4, n.3, p.86-97, 2009. 